jects tius affected placed in a separate chamber, the latter being provided with a powerful ventilating apparatus. We should not omit to say that we lately saw, at the London Hospizal, a patient of MIr. Ward, placed in one of these isolated rooms, which is provided with a large tube and mill for ventilation. The patient had first suffered from cancer of the lip; the ulcerated tumour had been removed, as was also, a little time afterwards, a cancerous gland under the jaw, in which the disease had recurred. The wound for the second operation had never healed, and a few months afterwards the whole of the left side of the submaxillary region was one mass of ulcerating cancer. The fotidity, as may easily be fancied, is very considerable; but as the patient is by himself, and the room well ventilated, no mischief is likely to occur.

\section{ST. THOMAS'S HOSPITAL.}

Encephaloid Disease of the Testicle; Removal of the Organ. (Under the care of Mr. LE Gros CLARK.)

Frour the consideration of encephaloid disease of bone, we shall turn for a moment to the same affection in the testicle. We see a great many cases of this kind in the hospitals of London, and beg to allude to a few of the more recent ones.

Robert S-, aged forty-four years, and a tailor by trade, was admitted June 8th, 1852, under the care of Mr. Clark. The patient has been twice married, has ten children, and generally enjoyed pretty good health. About three years before admission, the right testicle was caught in the chink left between two boards forming the seat of an arm-chair. This accident caused some pain in the part, but it soon went off, and it was only a twelvemonth after this injury that severe pain was felt in the organ, the latter having gradually enlarged. The pain, however, did not continue long, and soon disappeared altogether for another trelvemonth, when it recurred with redoubled intensity, assuming a decidedly lancinating character. The patient's wife bore him children during this period, and it is au interesting question whether the offspring are or are not at this time contaminated. The fits of pain became now more frequent, and lasted longer; but the tumour, though it increased much in weight, did not augment in size, the latter being about the dimensions of a clenched adult fist.

On the 19 th of June, Mr. Clark removed the testicle in the usual manner, the glands in the groin being quite free. On a section, the encephaloid nature of the disease was distinctly seen, the proper structure of the gland being completely obliterated. On the 28 th of June, nine days after the operation, the wound was almost healed.

Encelualoid Disease of the Testicle; Post-mortem Examination. (Under the care of Mr. Green.)

Mr. Green had, some time ago, under his care, a patient suffering from encephaloid disease of the testicle and from phthisis. The existence of the latter affection precluded any operative proceedings, and we beg to adduce the post-mortem examination, for three reasons:-1st. Because it is sometimes thought that two specific diseases (cancer and phthisis) are incompatible. 2nd. Because the patient exhibited the rare phenomena of cicatrized vomicx. 3rd. Because the testicle and the lumbar glands were contemporaneously affected with encephaloid cancer.

The post-mortem examination was conducted by $\mathrm{Dr}$. Bristowe, demonstrator of morbid anatomy to the hospital.

Frederick D-, aged fifty-two, shorthand-writer, was admitted Feb. 24, 1852, into George's ward, under the care of Mr. Green, and died April 7th, 1852. The testicle was as large as a cocoa-nut. The surface of the left lung presented several thickened and cicatrix-like marks; one at the apex had the ordinary appearance of cartilage thickening; and the lung st ructure beneath it was healthy. One or two of these, having distinctly the characters of cicatrices, were found on the lower part of the upper lobe, and the lung structure beneath presented either small cavities in process of cure, (their surface assuming the appearance of a serous membrane, ) or small, putty-like, calcareous deposits, surrounded by solidified lung structure. Two or three more cicatrices, with precisely similar characters, were found in the base of the lung. The pulmonary structure beaeath was simply solidified, tough, and of a slate colour. There were one or two more solin patches in the upper lobe, which might have been caused by some o!d inflammatory or tubercular deposits. The right lung was slightly puckered at the apex, and presented a distinct cicatrix, with a large putty-like tumour beneath it. About the middle of the upper lobe there was a solid mass, partly made up of tubercular deposit, and partly of the results of inflammatory changes around it.

The intestines were partially displaced by a tumour, about as large as a cocoa-nut, situated in the lumbar region, and beneath the mesenteric vessels, by which it was divided into two lobes; the third portion of the duodenum was lifted up by it, and strongly adherent. The testicle and the tumour in the right lumbar region were coutinuous by a chain of enlarged glands. The surface of the testicle was smooth, but that of the tumour in the lumbar region was much lobulated; they both presented almost similar characters on section, being made up of diffluent pulp, resembling softened brain, at some parts of an opaque white colour, at others of a brick-red, from infiltration of blood. The tumour in the abdomen was made up of distinct lobules, corresponding to the originally distinct glands, the extravasated blood being here more abundant than in the testicle. The separation of the testis from the epididymis was distinctly marked, the latter being much enlarged, and affected with encephaloid disease, but still retaining traces of its original convoluted appearance.

[In our last report from St. Thomas's Hospital, (ThE LANCET, June 19th, 1852, we omitted to state that the case of gangrene of both feet had been noted by MIr. Solly's dresser, Mr. G. D. Brown.]

\section{KING'S COLLEGE HOSPITAL.}

Encephaloid Cancer of the Testicle; Removal of the Organ. (Under the care of Mr. Pantridge.)

Turs patient, who is about thirty years of age, and of dissipated habits, has been suffering pain and uneasiness in the testis for the last two years. The affection had first been considered as hydrocele, and he had been tapped both by $\mathbf{M r}$. Henry Lee and Mr. Partridge. It became, however, evident that the accumulation of fluid $w$ as only incidental to a disease of the testicle. The man was re-admitted under the care of Mr. Partridge, in April, 1852, and as the tumour had much increased in size, and the lymphatic glands were not affected, Mr. Partridge removed the whole mass on the 1st of May. Before commencing the operation, a puncture was made so as to ascertain the nature of the growth; and as it was found solid, no fluid but a little blood escaping, the nature of the disease became sufficiently plain, though it still might have been encysted varicocele.

MIr. Partridge expressed a fear that sooner or later the disease would recur in the lumbar glands. On a section of the mass, which was about the size of an adult fist, all the characters of medullary cancer were distinctly seen. It should, however, be remembered, that in this case, as in a great many others, the accurate resemblance to brain cannot be said completely to exist, as the encephaloid structure in the testicle is much more resisting than brain substance. The patient has done extremely well; and it is to be hoped that he will not have soon to apply for re-admission.

\section{ST. GEORGE'S IIOSPITAL}

Encephaloid Disease of the Testicle presenting an Enchon. dromatous Induration.

(Under the care of Mr. Inenry Chardes Johnson.)

THE last case of encephaloid cancer of the testicle, to which we have now to draw attention, is peculiar, inasmuch as it show's what changes may, with time, take place in an originally encephaloid growth; attention to this case will probably present errors of diagnosis, which, in analogous in. stances, might easily be made.

The patient is a man about thirty years of age, who was admitted under the care of Mr. Johnson, in Feb. $1852 . \mathrm{He}$ presented a considerable enlargement of the left testicle, which had begun to appear about fifteen months before admis. sion; the organ had now reaclied the size of a large turkey's egg, but no pain had ever been felt in it. The man applied to Mr. Johnson principally to be relieved from the inconvenience of the weight and size of the enlarged testicle. A puncture made into the swelling was followed by no discharge of fluid; and though it was thought that the disease was of a malignant kind, the patient was reconmmended a course of mercury, which might be of benefit if the affection happened to be tubercular. The mercurial treatment had, however, no influence on the disease, and Mr. Johnson resolved to remove the encephalo: mass.

The operation was accordingly performed on the 26th of Feb., 1852, in the usual way, the patient being insensible 